\title{
Por entre redes e tramas: a indumentária de pescadores e maricultores da Freguesia de Santo Antônio de Lisboa (Florianópolis-SC)
}

Among threads and webs: the clothing of fishermen and shellfishermen the Parish of Santo Antônio de Lisboa (Florianópolis-SC)

[resumo] Este estudo teve como objetivo questionar a indumentária de pescadores e maricultores em vínculo com o exercício de suas atividades, bem como sua inserção, ou não inserção, social em uma sociedade de moda. Esses homens que, mesmo revestindo os corpos com roupas, se encontram - ao menos no momento laboral - à deriva da moda. No caso dos pescadores, é notável o desgaste e esmerilhamento dos trajes e do próprio corpo, que no presente trabalho - mas também nos trabalhos de Mauss, Vidal, Lynch e Strauss - é considerado parte constituinte da indumentária. 0 corpo ultrapassa o caráter biológico. É manipulado, moldável.

\section{palavras-chave}

Antropologia visual; indumentária; moda; cultura; pescador

[abstract] The present paper had as goal to question the clothing of fishermen and shellfish producers linked to their activities, as well as their social insertion, or not, in a fashion society. Those men, who even covering their bodies with garments, are found - at least during labor - adrift to fashion. Regarding the fishermen, are remarkable: the faded and worn out clothes, as well as the body, which in this work - but also in the work of Mauss, Vidal, Lynch and Strauss - is considered a constituent of clothing. The body surpasses the biological character. It is manipulated, shaped. 
Introdução

0 presente trabalho consiste em relato acerca da captura de uma série de dez imagens realizadas nos meses de janeiro e fevereiro do ano de 2014. As fotografias intentam apresentar pescadores e maricultores da Freguesia de Santo Antônio de Lisboa, localizada no noroeste da llha de Santa Catarina, no preparo e no retorno das atividades pesqueiras ao mar e no trabalho de soltura dos cachos de mariscos. De modo mais especifico, as imagens apresentam a indumentária desses homens, a fim de questionar sua roupagem vinculada ao exercício de suas atividades pesqueiras e maricultoras, bem como sua inserção social em uma sociedade de Moda (SANT'ANNA, 2007).

Este ensaio não tem a pretensão de abordar a Antropologia da Indumentária como disciplina especifica. Por outro lado, recusa-se a utilizar a expressão Antropologia da Moda, uma vez que os pescadores retratados na série fotográfica apresentam-se como figuras à deriva de uma lógica da Moda. Ou, como preferiria Lipovetsky (2007), caracterizados pelo próprio Sistema de Moda como marginais a este. Convém, assim, incorporar a indumentária às análises da visualidade e da cultura material, já que estas dimensões são passiveis de investigação nas já existentes correntes antropológicas.

Intenta-se adentrar e entender a indumentária como vocabulário, o qual pode ser arranjado e composto de diversas maneiras, a fim de expressar uma noção de individuo e de grupo. "O fato é que, independentemente de qualquer época ou lugar, a roupa sempre foi um diferenciador social, uma espécie de retrato de uma comunidade ou classe" (FEGHALI, 2001, p. 37). As apreensões que os indivíduos têm da sociedade, bem como as posições que nela eles ocupam, fazem-nos interferir na indumentária. 0 vestir funciona como uma maneira de marcar pertencimento de determinado membro em determinada categoria. Além disso, gênero, idade, classe, visão política, etc. são informações caras à indumentária e à corporalidade.

\section{Os maricultores da Freguesia de Santo Antônio de Lisboa, Florianópolis}

Santo Antônio de Lisboa é um distrito de Florianópolis, na llha de Santa Catarina, composto por quatro bairros: Santo Antônio de Lisboa, Cacupé, Sambaqui e Barra do Sambaqui. Uma das primeiras freguesias da cidade, foi criada no ano de 1751, supostamente sob invocação de Nossa Senhora das Necessidades - que até hoje dá nome à irmandade católica. A colonização da cidade, iniciada no século XVIII, é marcantemente de familias açorianas, o que confere particularidades ao local.

Apesar de a comunidade vir recebendo moradores recentemente, grande parte da população é nativa da região e as familias conhecem sobremaneira umas às outras. Além do clima de cidade pequena, a arquitetura açoriana consideravelmente preservada, composta por casas tombadas e a histórica igreja local, atrai turistas e imprime 0 ar pitoresco da localidade. As principais e mais tradicionais atividades da comunidade consistem na feitura manual da renda de bilro e na pescaria; a primeira era uma ocupação feminina e a segunda, executada quase unicamente por homens.

Ainda atualmente, a Freguesia de Santo Antônio de Lisboa caracteriza-se em um cenário florianopolitano por suas atividades pesqueiras. Nas últimas décadas, a localidade foi inserida na rota turistica estadual por seus restaurantes de frutos do mar e hoje é nomeada de Rota Gastronômica do Sol Poente. Todos os bairros que compõem a freguesia são conhecidos pelos restaurantes de frutos do mar - que atraem florianopolitanos e turistas. A localização desses restaurantes deve-se, principalmente, à atividade pesqueira dos moradores da freguesia, que ocorre desde o século XVIII.

Diante das recentes transformações, o pescador ainda se apresenta como uma figura - uma quase personagem - que marca a duração de uma cidade que não para de se reinventar. A remota atividade pesqueira agora divide areias e mares com a moderna atividade maricultora. Esta, posteriormente introduzida, trata do cultivo artificial de mariscos e ostras, já que não se dá mais de forma espontânea. A modernização da prática sugere o conceito de hibridização de Canclini (2008), uma vez que a maricultura consiste num modo a reconverter um patrimônio, inserindo-o em novas relações e condições de produção e mercantilização.

Como apresentado, a maricultura é parte relevante da economia da região, inclusive o estado de Santa Catarina concentra a maior parte do cultivo de moluscos, e é o maior produtor de mexilhões da América Latina. Sendo assim, também é mais expressivo o número de homens da região que se ocupam da maricultura 
do que daqueles que se ocupam da pesca. De modo geral, e como perceber-se-á nas fotografias, os pescadores são normalmente homens de mais idade. A atividade de maricultura, por sua vez, também emprega homens de meia-idade.

\section{Indumentária pesqueira e maricultora: registros fotográficos}

0 registro fotográfico que impulsionou a redação deste texto e considerações enfocou apresentar a indumentária dos pescadores e maricultores da freguesia. Nele, esses trabalhadores encontram-se em quatro pontos diferentes nas praias de Santo Antônio de Lisboa e Sambaqui. Fazem parte do cenário proposto para este ensaio os homens Adriano, Biro-Biro, Cadinho, Reginaldo, Airton, Hamilton e Nei. Todos eles são moradores dos bairros e personagens conhecidas e, de modo geral, apresentam genuinamente o vestir de pescadores e maricultores da localidade.

Como já mencionado, as imagens nos apresentam maior número de maricultores do que de pescadores. Isso é expressivo das mudanças ocorridas na própria freguesia, as quais explicitam mudanças na relação dos homens com o mar. Enquanto a pesca artesanal é ocupação tradicional de homens na Ilha de Santa Catarina e, especificamente na Freguesia de Santo Antônio de Lisboa, a maricultura é atividade contemporânea, uma característica dos processos modernos de sistematização e planejamento do extrativismo maritimo. A análise das vestimentas é explícita ao demarcar essa diferença. Os maricultores Reginaldo e Airton (Figs.1 e 5) utilizam avental plástico sobre a indumentária para a atividade de soltura e limpeza dos mariscos, o que destoa da indumentária descoberta dos pescadores.

De modo compartilhado, as vestimentas utilizadas pelos pescadores e maricultores em serviço apresentam-se sujas, surradas e gastas. Entregam a funcionalidade delas esperada: a de servir à cobertura do corpo, mas sem empecilhos, de modo que não interfiram nos movimentos realizados em alto-mar e à beira-mar. São bermudas largas, de material fino e sintético, com baixa absorção de água, e camisetas de malha, leves, frescas e altamente confortáveis, que aparecem nas versões com e sem mangas.

A tonalidade clara das camisetas que - nem sempre - vestem o tronco dos pescadores alude à antiga crença de que cores escuras esquentariam mais à presença do sol. Assim, cores claras ofereceriam o frescor durante os esforços da profissão. Maior frescor seria garantido também pela ausência das regatas e camisetas, tendo o próprio torso nu - magro e bronzeado - como indumentária característica do grupo.

Figura 1: Reginaldo de avental lava os mariscos. / Wearing an apron, Reginaldo washes the clams.

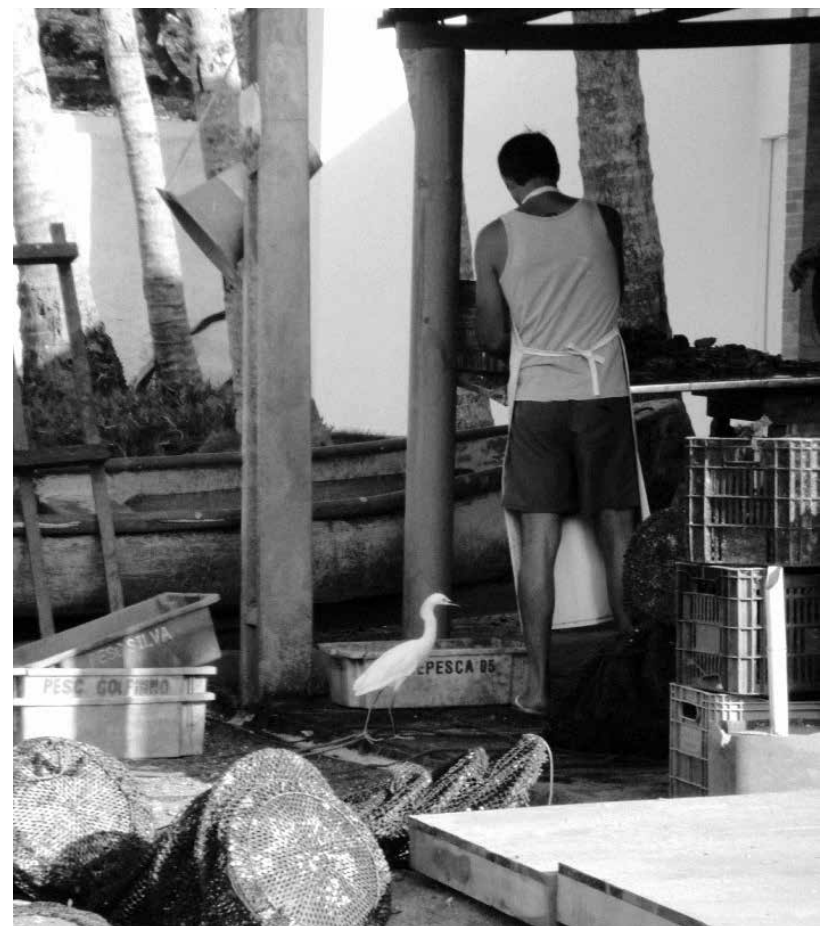


As peças brancas e cinza vestem os corpos de Reginaldo (Fig.1), Biro-Biro (Fig.2), Nei (Fig. 3) e Adriano (Fig. 4). Airton (Fig. 5) usa bermuda com notas acinzentadas e no torso uma blusa - modelo polo - em tom de laranja enfraquecido pelo sol. A perda da vivacidade tonal das roupas pela exposição solar é visivel na indumentária de Hamilton. Trajando bermuda verde e calção verde, a tonalidade das peças é menos contrastante com o mar cinzento do que a árvore à esquerda que emoldura a composição (Fig. 5).

Cadinho, maricultor e o homem mais jovem do grupo retratado, é o que se veste de modo mais destoante (Fig. 6). As cores do calção são intensamente mais vibrantes do que as dos companheiros. Em roxo intenso contornado por detalhes em amarelo, também tem forma que foge ao padrão dos demais pescadores e maricultores. Em modelo mais longo na perna, o calção poderia ser caracterizado com uma bermuda de surfe. $E$, se não fosse retratado na ação das atividades de maricultura, poderia ser facilmente confundido com um banhista.

Figura 2: Biro-Biro leva embarcação ao mar. / Biro-Biro leads the boat to the sea.

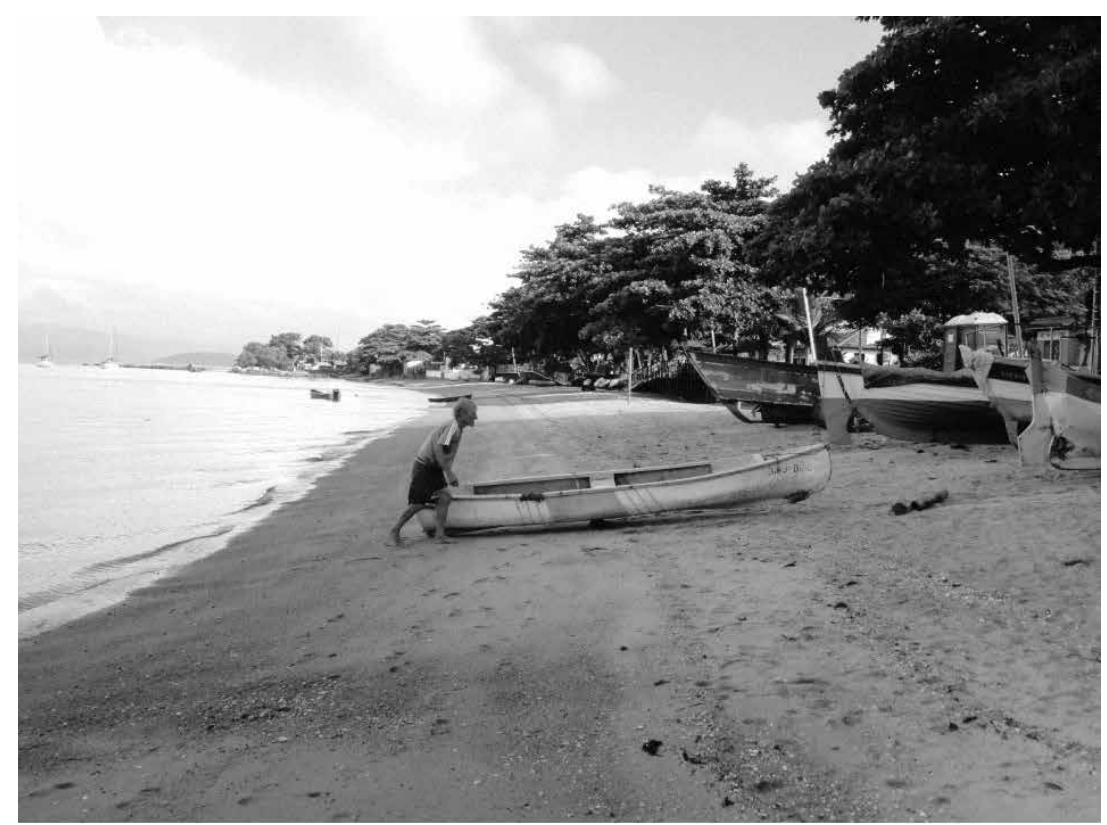

Fonte: Amanda Queiroz Campos (janeiro de 2014).

As pedras, as redes, o reboco mal revestido, a madeira escurecida dos ranchos, a areia grossa cinzenta (Figs. 3, 5, 6 e 7). 0 próprio azul do mar fora acinzentado na composição. Nesta cinza imagem, os barcos são os elementos que mais se destacam, por vezes ainda acrescidos de lonas com coloração vibrante. A impressão acinzentada geral contrasta para além dos barcos, com a tonalidade ainda que esmaecida das camisetas e bermudas que vestem a pele de tom bronzeado daqueles homens.

Vale notar que as caracteristicas de magreza e bronzeamento são altamente valorizadas no contexto da sociedade contemporânea - pós-industrial e capitalista. Porém, a valorização esquiva-se dos pescadores por fluidas nuances destes atributos. A magreza e os delgados músculos valorizados pela cultura contemporânea e urbana são característicos de atividades físicas de lazer, como: corrida, caminhada e exercícios de musculação em academias. Trata-se do "corpo-modelo que hegemoniza as imagens difundidas pelos meios de comunicação", corpos dóceis (KATZ, 2008, p. 74; FOUCAULT, 1997). 
0 corpo físico dos trabalhadores, apesar de magro, apresenta desvios em relação ao que é proposto como padrão pela sociedade contemporânea. A magreza daqueles corpos nem sempre acompanha um abdômen reto e sem gorduras. Os magros músculos diferem dos valorizados pela prática da academia. Denunciam a atividade repetitiva característica do trabalho árduo, não do lazer. São corpos que quase escapam ao fetiche sexual no campo da moda, são inadequados ao seu exercício (VILLAÇA, 2006; STEELE, 1997). Como propõe Denizard (apud VILLAÇA, 2006), este tipo de corpo seria um empecilho para a moda.

Figura 3: Nei em seu rancho com samburás. / Nei in his ranch with samburás.

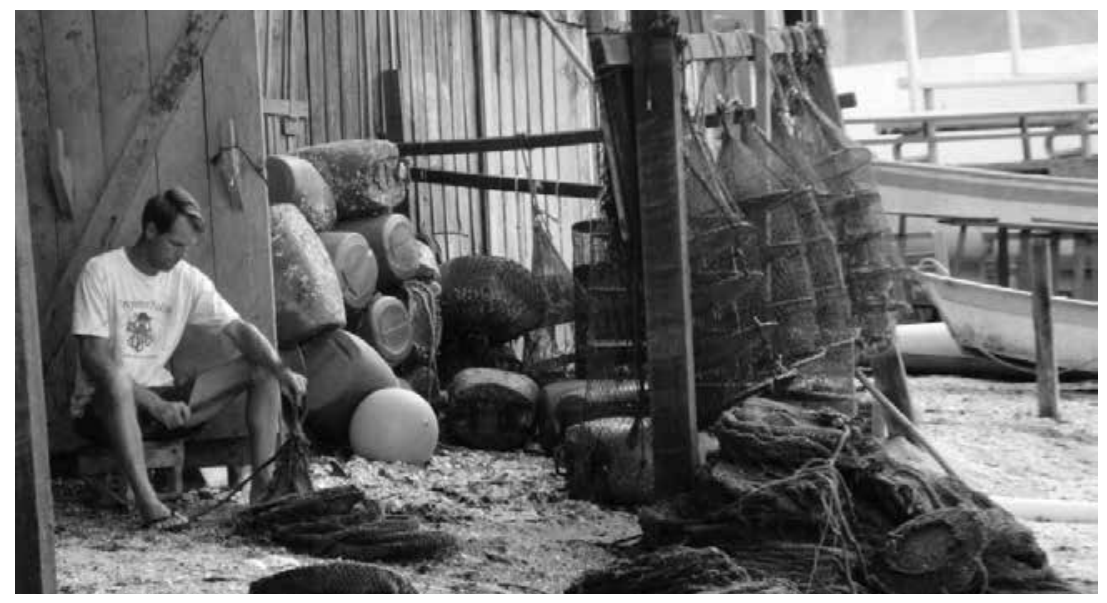

Fonte: Amanda Queiroz Campos (janeiro de 2014).

Figura 4: Adriano embarca a rede. / Adriano boards the web.

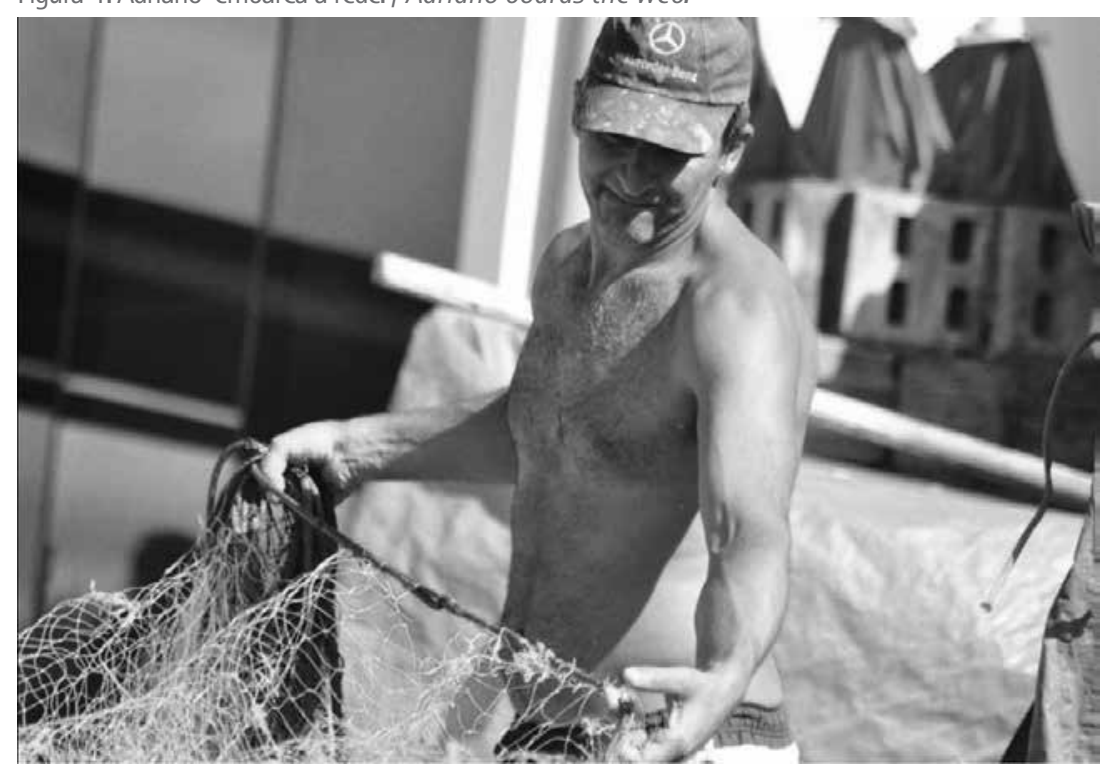

Fonte: Celso Martins. 
0 bronzeamento positivado pela atual sociedade é resultante de longas horas estendidas sobre a areia, em dissonância com os corpos quase tostados pelo sol, característicos pelo intenso trabalho ao ar livre. 0 bronzeamento dos pescadores é negativizado por sua intensidade excessiva de exposição ao sol, intensificada pela maresia. Marcas indiciais de camisetas e bermudas de proporções diferentes contribuem para o bronzeado pouco valorizado - por vezes, ridicularizado - dos pescadores.

Silva (2000) propõe a indumentária como aspecto fundamental para os estudos de alteridade e identidade no contexto da Antropologia Cultural. Também os escritos antropológicos evidenciam que a indumentária ultrapassa aspectos funcionais, mas corresponde a parte indissociável do habitus (BOURDIEU, 2003) humano. De uma perspectiva da antropologia, segundo Lynch e Strauss (2007), a aparência e o ato de vestir são materializações visiveis dos significados e sistemas culturais. Ao estudar a arte gráfica entre os Kayapó-Xikrin do Cateté, Vidal (1992) elucida como os grafismos sintetizam os valores mais altos da cultura Kayapó - não consistem em traços culturais abstraídos do contexto, mas, de modo oposto, são símbolos com referenciais, consistem em um sistema. Vidal (1992) investiga a relação entre a estrutura social e o modo de tratar o corpo.

Para Le Breton (2007), o corpo também deve ser problematizado para além da dimensão biológica, pois

engendra aspectos físicos aqueles com menor percentagem de manobra, e envolve simbolismos provisórios, em voga no meio sociocultural de cada época e situação. A existência do corpo no mundo implica as dimensões pessoal, social e cultural, interferindo em seus modelos de ação e representação (LEAHY, 2015, p. 5).

Ainda sobre tratar o corpo, Mauss (1974) apresenta a categoria de técnicas corporais para referenciar o corpo como objeto técnico inicial do homem e ao explicitar as maneiras pelas quais o homem e as sociedades servem-se de seus corpos. Os pescadores e os maricultores investem na força física e no bronzeamento de seus corpos por meio das atividades que exercem. 0 trabalho molda a forma como os seus corpos se apresentam. Corpos magros e bronzeados, contudo corpos não erotizados. São corpos reais do trabalho árduo. As imagens apontam poses que não visam seduzir, mas expressar a gestualidade laboral.

As imagens perpassam a intenção de que estes homens apresentados não teriam cuidado com a aparência, que naquele mundo do labor não restaria tempo para um cuidar de si. Em síntese, a imagem sublinha desleixo. Em uma época em que as pessoas se arrumam para se apresentar socialmente, incluindo a esfera do trabalho, estes pescadores desarrumam-se para trabalhar. Parecem não ter apreço pela aparência. As figuras 7 e 8 apresentam roupas deixadas no rancho de Cadinho, provavelmente para serem usadas na atividade pesqueira e maricultora. Acredita-se que suas melhores vestimentas destinem-se a outros fins. Como o caso de Biro-Biro, que se despe da camiseta da marca Adidas ${ }^{\circledR}$ ao adentrar o mar (Fig. 1).

É notável a inserção de uma lógica de marcas que é apropriada e ressignificada por estes pescadores. Adriano usa um boné (Fig. 4) com a assinatura visual da Mercedes-Benz ${ }^{\circledR}$ - marca alemã de automóveis de luxo. A apropriação da marca Mercedes-Benz ${ }^{\circledR}$ que induz a um universo de sofisticação e luxo contrasta com a figura do pescador que o porta, pois é um homem simples e de origem humilde. Entretanto, apesar de este pescador provavelmente ser incapaz de vir a consumir um automóvel da marca, ele possui contato com ela e com o universo que ela conota, por meio dessa peça de vestuário. 
Figura 5: Airton limpa os mariscos em Santo Antônio de Lisboa. / Airton washes the clams in Santo Antônio de Lisboa.

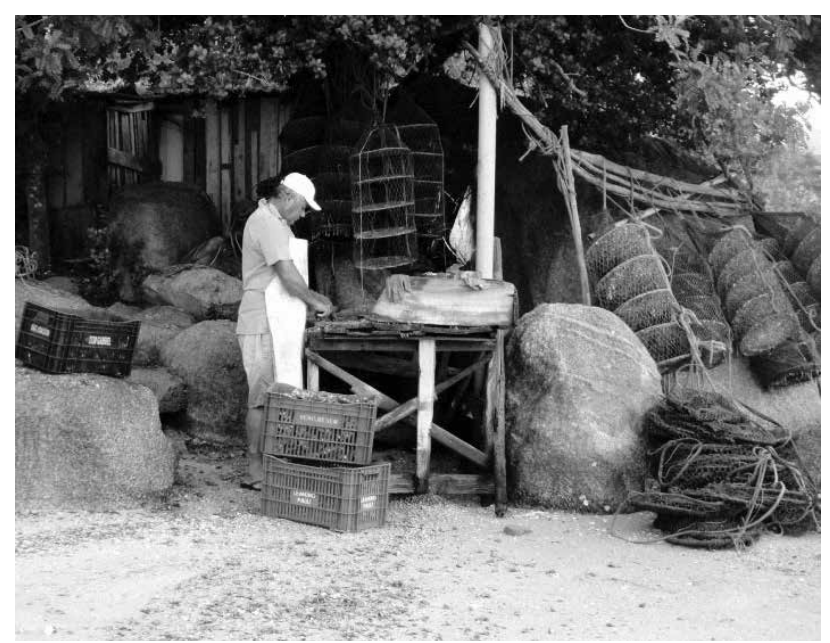

Fonte: Amanda Queiroz Campos (janeiro de 2014).

0 boné apresenta aspecto de desgaste e muitas manchas em toda a sua extensão, além de leve descoloração causada pela exposição ao sol. 0 próprio desgaste realizado pelos trabalhos do pescador e pela incidência solar ressignificam a marca Mercedes-Benz ${ }^{\circledR}$, uma vez que neste uso e nestas condições abdica da sofisticação e destina-se ao uso funcional e laboral, em conjunto com a bermuda também esmerilhada.

Figura 6: Cadinho confere as redes dos samburás. / Cadinho checks the samburás' nets.

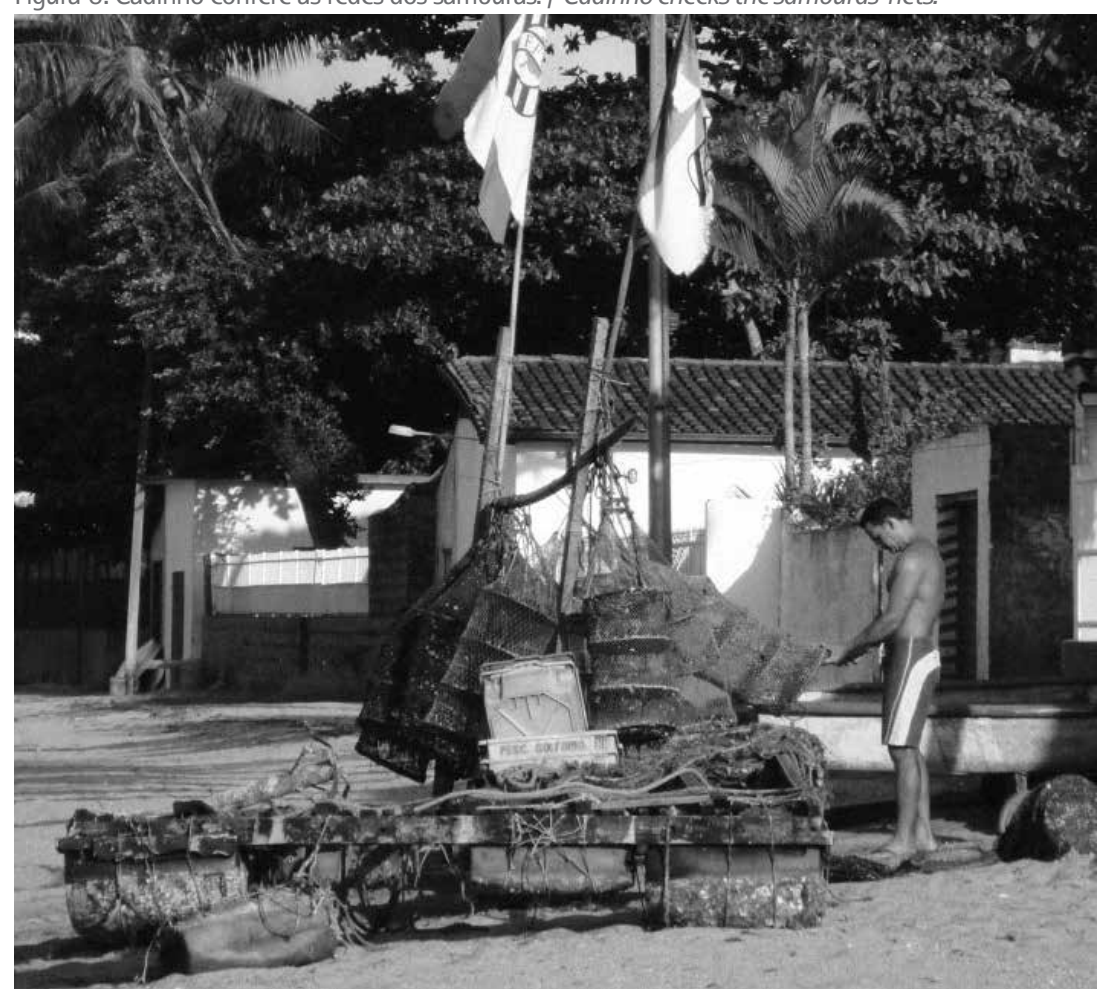

Fonte: Amanda Queiroz Campos (janeiro de 2014). 
Para o estudo da Moda e da indumentária no campo da Antropologia, é imprescindivel considerar as relações sociais que tramitam pelas peças. Castilho e Martins (2005, p. 23) sugerem que os objetos de vestuário sejam percebidos como representações metonímicas daqueles que os possuem. Tais objetos são metafóricos do próprio indivíduo, por meio de associações em analogias, no tempo e no espaço da sociedade contemporânea. As vestimentas são, igualmente, interfaces das relações do indivíduo consigo mesmo e com o outro. Como elementos da cultura, constroem a teia de significados que Geertz (2008) considera organizar a vida sociocultural.

Figura 7: Calça de moletom sobre barco. / Sweatpants over boat.

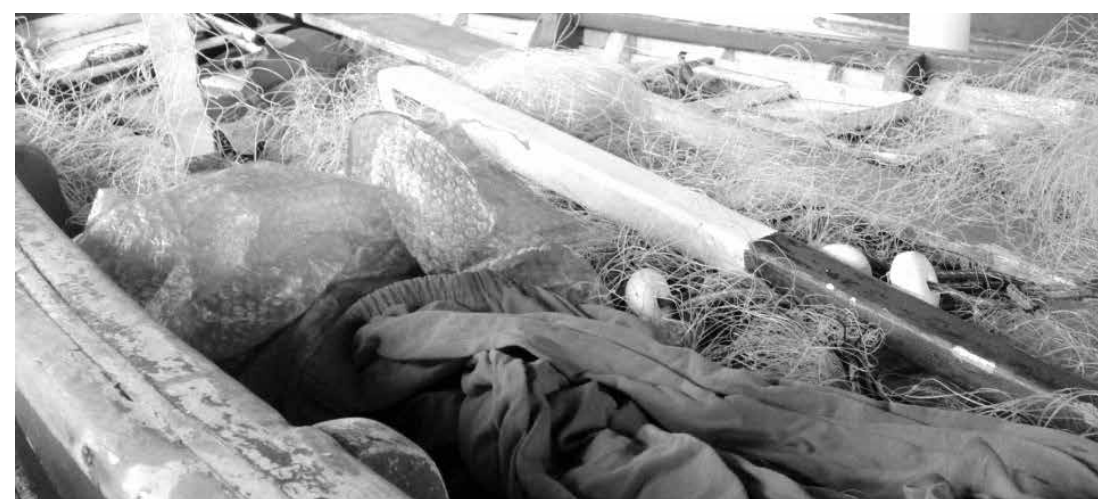

Fonte: Amanda Queiroz Campos (janeiro de 2014).

No caso do boné e da camiseta de marca, ficam sugeridas as trocas e doações que comumente ocorrem entre camadas sociais mais abastadas - como a classe média que também habita a freguesia - e os trabalhadores da localidade - classe baixa. Vê-se que a indumentária expressa e reproduz uma série de relações sociais, como no caso de donativos de produtos de marca entre as classes sociais. 0 novo é positivado por um Sistema de Moda (SANT'ANNA, 2007), desta feita, tudo o que é considerado velho ou obsoleto é descartado, repassado ou destinado ao uso doméstico por aqueles com poder aquisitivo para renovar continuamente seus guarda-roupas.

Com isso, há imbricações de produtos e marcas de alto valor, mas que foram desvalorizados pelo tempo e tratos, em grupos com menor acúmulo de capital, como estes pescadores e maricultores. Há ainda uma lógica de consumo não hegemônica (RIBEIRO, 2010) que comercializa produtos falsificados e que estampam - sem aprovação das marcas oficiais - as assinaturas visuais de marcas de luxo, tais como Mercedes-Benz ${ }^{\circledR}$ e Adidas ${ }^{\circledR}$. A oferta a baixo custo vinculada ao amplo acesso à informação de marcas internacionais as torna acessiveis - e ressignificadas - mesmo a camadas menos abastadas da população.

Figura 8: Blusas e calções no rancho de Cadinho. / Shirts and trousers in Cadinho's ranch.

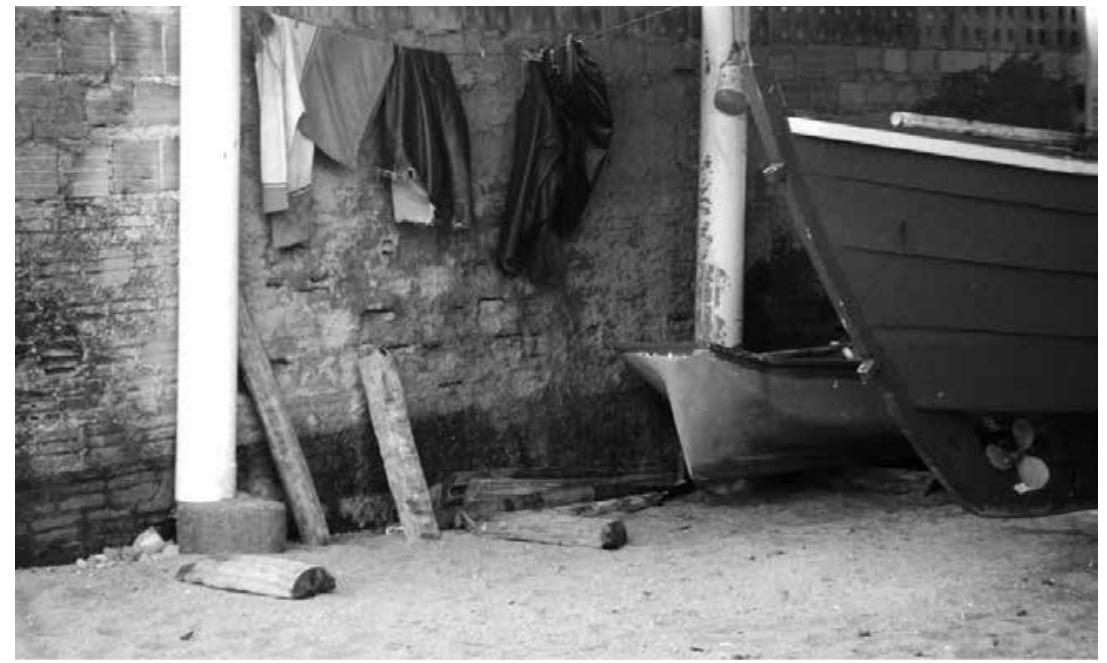

Fonte: Amanda Queiroz Campos (janeiro de 2014). 
Uma mesma roupa difere significados dentro de grupos sociais diversos, por meio

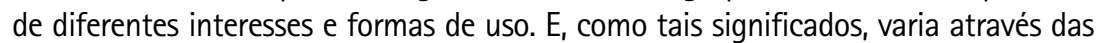
relações sociais e de poder dentro da sociedade classificada como complexa. A posição que determinado indivíduo ocupa dentro de uma estrutura social pode ser lida por meio da observação, análise e interpretação de sua indumentária (ECO, 1999). "A moda, como outros processos culturais, produz significados, constrói posições de sujeito, identidades individuais e grupais, cria códigos que guerreiam entre si, num fórum que se globaliza progressivamente" (VILLAÇA, 2006, p. 23). 0 sistema de Moda serve como palco para relações entre grupos e as peças de vestuário e acessórios funcionam como intermédios simbólicos das visibilidades ou invisibilidades de grupos sociais estudados.

Nas seleção de fotos, apresenta-se um varal improvisado no rancho do maricultor Cadinho (Fig. 8). Penduradas no varal, duas calças impermeabilizadas - feitas provavelmente de tecido fino de algodão revestido por camada emborrachada - uma na cor azul e outra preta; uma blusa no mesmo material de cor azul intenso e um blusão de mangas compridas nas cores branco e areia. Também no rancho de Cadinho, sobre uma das embarcações repousa uma calça de moletom de cor urucum, que está moIhada (Fig. 7). As imagens indicam que estas peças são aquelas guardadas no rancho para o uso laboral. Ou seja, são peças que não ocupam o guarda-roupa social de Cadinho, de Reginaldo e de seus companheiros, servindo estritamente como indumentária para o trabalho no mar.

\section{Considerações sobre a indumentária dos pescadores e maricultores}

0 ato de vestir aponta escolhas mais amplas, revela diferenças e semelhanças, constitui identidades e alteridade. "Sabemos que as vestimentas servem como elementos da atestação de pertencimentos e, tanto ontem quanto hoje, elas fazem parte do processo de constituição das identificações sociais" (CIDREIRA, 2005, p. 60). Sendo assim, o corpo e a indumentária funcionam como recursos para a construção identitária e de alteridade, meio de comunicação, expressão e também de classificação e discriminação.

Como representações visuais e simbólicas, as roupas podem identificar camadas sociais, profissões, idade e sexo das pessoas, bem como diferenciar um grupo social de outro. No caso dos pescadores, o que frisa sua camada social é o desgaste das roupas e do próprio corpo, que no presente trabalho - mas também compartilhado nos trabalhos de Mauss, Vidal, Lynch e Strauss - é considerado parte constituinte da indumentária. 0 corpo ultrapassa o caráter biológico. É manipulado, moldável, moldado sob a cultura. Para Katz (2008, p.69),

\footnotetext{
Um corpo nunca existe em si mesmo, nem quando está nu. Corpo é sempre um estado provisório da coleção de informações que o constitui como corpo. Esse estado vincula-se aos acordos que vão sendo estabelecidos com os ambientes em que vive.
}

Ainda em relação à Antropologia, Piault (1994) afirma a necessidade de retratar grupos e aspectos muitas vezes marginais. A escolha dos pescadores da Freguesia de Santo Antônio de Lisboa busca trazer à superficie estes homens em sua atividade mais cotidiana: o trabalho.

A relação dos pescadores da freguesia com a natureza é muito próxima e respeitosa. As árvores dão noção de proteção à figura humana. As encostas os abrigam, os acolhem. No retrato de Airton, o verde das árvores e a parede de pedras que forma a encosta o resguardam (Fig. 5). Privam-no do sol escaldante nas horas da soltura dos mariscos. Filtram para ele o vento forte que arrasta rajadas de areia contra a pele. Acima de tudo, o mar lhe provê. 
As fotografias tomadas e selecionadas qualitativamente intentam revelar, principalmente através da ênfase na indumentária, a condição braçal e pré-industrial do trabalho dos pescadores. Um real que marca permanência, mas é uma permanência que aos poucos vai tendo seus contornos borrados. A inserção dos maricultores - que ganham expressividade em número - é reveladora das modificações que o cenário do extrativismo maritimo enfrenta na Freguesia de Santo Antônio de Lisboa.

Considero válido frisar que estes aqui apresentados - Cadinho, Biro-Biro, Nei, Reginaldo, Hamilton, Adriano, Airton - são pessoas. Pessoas que pescam de modo artesanal, homens que extraem do mar alimento com a maricultura. Os maricultores, apesar de já investirem no cultivo, não estão diretamente vinculados aos processos industriais de produção e não são funcionários de grandes empresas. São permanências de um tempo, de uma Florianópolis que quase desapareceu, que foi reinventada. Uma cidade que, como cenário, se vê dissolver.

0 trabalho do homem do mar é visto como um trabalho nobre. Um trabalho ainda não corrompido por uma lógica fabril, industrial. 0 pescador e o maricultor podem ser apontados como aqueles homens que não foram tirados de seus habitats, os homens que não foram tirados de suas terras. Todos esses homens que emprestaram suas imagens e nomes na composição deste pequeno ensaio são homens que ainda moram nos terrenos de seus antepassados. Nas fotografias, estas figuras humanas têm a cabeça inclinada para o chão, para o mar, em uma face de quase respeito, quase devoção ao local de onde retiram seu sustento.

Os pescadores e os maricultores da Freguesia de Santo Antônio de Lisboa hoje vivem em uma chamada Florianópolis moderna, uma cidade do século XXI. Contudo, estes homens guardam em seu trabalho algo que caracteriza a forte relação do homem com a natureza. Resquícios de algo ainda não tocado pela - tão temida por Aby Warburg - era das máquinas (WARBURG, 2005).

Costumeiramente, na antiga Florianópolis, a indumentária para ir à praia era a roupa já usada, já surrada pelo tempo. Atualmente, veem-se nas praias da cidade pessoas vestindo uma chamada moda praia: roupa de banho, chapéus, bolsas, sandálias e saídas de praia. Tal indumentária constitui um dos principais produtos de exportação do país. 0 Brasil também vende uma moda e um corpo praia, e neste contexto o corpo é objeto vendável, objeto de trabalho da beleza, e aspecto pelo qual cada um toma responsabilidade. Neste contexto, o culto ao corpo é propagado pela cultura fitness da área da "saúde" e pela cultura de consumo de moda (LEAHY, 2015).

A cidade de Florianópolis também é vendida através de uma moda praia. Vende-se um ver e ser visto em suas brancas faixas de areia. Faixas de areia antes majoritariamente ocupadas por homens que carregavam outras tramas. As antigas tramas não eram feitas de lycra ${ }^{\circledR 1}$, suplex ${ }^{\circledR 2}$ ou tecidos inteligentes. Suas tramas eram de nylon ${ }^{\circledR 3}$, eram redes pesqueiras.

\section{NOTAS}

${ }^{[1]}$ Lycra $^{\circledR}$ é um fio sintético de elastano desenvolvido pela empresa DuPont ${ }^{\circledR}$. 0 fio sempre é combinado com outros fios, criando tecidos de elasticidade e durabilidade, possibilitando o movimento. 0 fio retém a forma e pode ser esticado até sete vezes seu comprimento inicial. Tais propriedades o tornaram o fio mais utilizado na fabricação de roupas esportivas e de praia.

${ }^{[2]}$ Suplex ${ }^{\circledR}$ é uma fibra resistente, flexivel e macia desenvolvida pela DuPont Sudamerica ${ }^{\circledR}$. Em comparação com a lycra ${ }^{\circledR}$, a fibra de suplex ${ }^{\circledR}$ é mais flexível, uma vez que pode ser estirada em todas as direções. De toque macio, similar ao do algodão, tecidos de suplex ${ }^{\circledR}$ dão forma ao corpo, aderindo-o, conferindo conforto tanto nos movimentos quanto em relação à temperatura.

${ }^{[3]} 0$ fio de nylon ${ }^{\circledR}$, primeiro fio têxtil sintético, foi desenvolvido na década de 1930 . Consiste em um polímero, do qual se produzem velcro e tecidos usados em meias-calças. 0 nylon teve popularidade na época, sendo utilizado inclusive em roupas de praia. Com o desenvolvimento de fios mais confortáveis, como a lycra ${ }^{\circledR}$ e o suplex ${ }^{\circledR}$, os biquínis passam a ser feitos com tais materiais. Neste texto, a referência ao nylon faz-se pelos fios de nylon utilizados pelos pescadores em suas redes e pelos maricultores em seus samburás - ou ainda em cordas e cordões visíveis nas diversas imagens. 


\section{REFERÊNCIAS}

BOURDIEU, Pierre. A dominação masculina. Rio de Janeiro: Bertrand Brasil, 2003.

CANCLINI, Néstor Garcia. Culturas híbridas: estratégias para entrar e sair da modernidade. 4. ed. São Paulo: Edusp, 2008.

CASTILHO, Kathia MARTINS, Marcelo M. Discursos da Moda: semiótica, design e corpo. 2. ed. rev. e atual - São Paulo: Editora Anhembi Morumbi, 2005.

CIDREIRA, Renata Pitombo. Os sentidos da moda:vestuários, comunicação e cultura. São Paulo:

Annablume, 2005

ECO, Umberto. 0 hábito fala pelo monge. In: ECO, Umberto. Psicologia do vestir. 3. ed. Lisboa: Assirio e Alvim, 1999

FEGHALI, Marta Kasznar. As engrenagens da Moda. Rio de Janeiro: Senac, 2001.

FOUCAULT, Michel. Vigiare punir. Petrópolis: Vozes, 1997.

GEERTZ, Clifford. A interpretação das culturas. Rio de Janeiro: LTC, 2008.

KATZ, Helena. Por uma teoria crítica do corpo. In: OLIVEIRA, Ana Cláudia de; CASTILHO, Kathia. (Orgs.) Corpo e moda: por uma compreensão do contemporâneo. Baureri: Estação das Letras e Cores Editora, 2008. pp. 69-74.

LEAHY, Renata Costa. A moda e o padrão de beleza corporal em contextos culturais: primeiras considerações. Colóquio de Moda. XI. 2015. Curitiba. Anais... São Paulo/SP: ABEPEM, 2015. pp. Disponíve em: < http://www.coloquiomoda.com.br/anais/anais/11-Coloquio-de-Moda_2015/ARTIGOS-DE-GT/ GT03-CORPO-MODA-E-COMUNICACAO/GT-3-A-MODA-E-0-PADRAO-DE-BELEZA-CORPORALpdfs. Acesso em: 20 set. 2015.

LE BRETON, David. A sociologia do corpo. Rio de Janeiro: Editora Vozes, 2007.

LYNCH, Anette STRAUSS, Mitchell D. Changing Fashion:A Critical Introduction to Trend Analysis and Meaning. Oxford/New York: Berg, 2007.

MAUSS, Marcel. As técnicas corporais. In: MAUSS, Marcel; LEVI-STRAUSS, Claude, 1908. Sociologia e antropologia. São Paulo: EPU/Edusp, 1974.

PIAULT, Marc-Henri. Antropologia e a passagem à imagem. In: Catálogo da Mostra Internacional do Filme Etnográfico. Rio de Janeiro, 1994.

RIBEIRO, Gustavo Lins. A globalização popular e o sistema mundial não hegemônico. Revista Brasileira de Ciências Sociais, V. 25, n. 74, outubro/2010. p. 21-38.

SANT'ANNA, Mara Rúbia. Teoria de Moda: sociedade, imagem e consumo. Barueri: Estação das Letras, 2007.

SILVA, Tomaz Tadeu da. Identidade e diferença: a perspectiva dos estudos culturais. 6 . ed. Rio de Janeiro: Vozes, 2000.

STEELE, Valerie. Fetiche: moda, sexo \&t poder. Rio de Janeiro: Rocco, 1997.

VIDAL, Lux. A pintura corporal e a arte gráfica entre os Kayapó-Xikrin do Cateté. In: VIDAL, Lux B. (Org.). Grafismo indígena. São Paulo: Studio Nobel; Fapesp; Edusp, 1992.

VILLAÇA, Nizia. A cultura como fetiche, corpo e moda. In: VILLAÇA, Nizia; CASTILHO, Kathia. (Orgs.). Plugados na moda. São Paulo: Editora Anhembi Morumbi, 2006. p. 23-29.

WARBURG, Aby. Imagens da região dos índios Pueblos da América do Norte. Concinnitas:Arte, Cultura e Pensamento ano 6, v.1, n. 8. Rio de Janeiro: UERJ, 2005. p. 8-29. 